Retraction announcement about the article "The perceptions of nurses in their management of patients experiencing anxiety”

This article has been retracted at the request of the authors and the publisher. The Publisher and the authors would like to apologize for any inconvenience caused. 


\title{
The perceptions of nurses in their management of patients experiencing anxiety
}

\author{
S. Webster ${ }^{1}$, S. Gallagher ${ }^{1}$, Peter Brown ${ }^{2}$, J. Evans ${ }^{1}$, M. Flynn ${ }^{3}$, V. Lopez ${ }^{4}$ \\ 1. School of Nursing, Australian Catholic University, New South Wales, Australia. 2. Charles Darwin University, Darwin, \\ Australia. 3. Special Mental Health Services for Older People, Northern Sydney, New South Wales, Australia. 4. Australian \\ National University, Australian Capital Territory, Australia.
}

Correspondence: Sue Webster. Address: School of Nursing, Australian Catholic University, New South Wales, Australia. Telephone: 61-297-392-387. Email: sue.webster@acu.edu.au

Received: November 26, 2011

Accepted: December 28, 2011 Published: August 1, 2012

DOI : $10.5430 /$ jnep.v2n3p38

URL: http://dx.doi.org/10.5430/jnep.v2n3p38

\begin{abstract}
Objective: The purpose of this qualitative study is to explore and describe mental health nurses' interventions in the management of patients who were experiencing anxiety in two inpatient mental health hospital facilities.

Method: For this study, data were collected through in-depth interviews with nursing staff who were working in these two inpatient mental health facilities within the same health service. Nurses' reflections on what strategies they perceived to be effective nursing interventions for patients experiencing anxiety were the focus of the study. Thirty nurses participated in the study; of these were three males (3) and twenty-seven females (27). Levels of experience varied from 1-25 years.

Results: The results highlighted the importance of assessment, interpersonal skills and empathy, and the over-arching core concept of the importance of developing a therapeutic relationship with patients. The results identified the importance of facilitative mental health nurse/patient interactions to assist in the promotion, maintenance and restoration of patients' mental health.

Conclusions: This preliminary study suggests that appropriately educated and clinically supervised mental health nurses can provide effective early interventions to patients who are experiencing anxiety in hospital settings. The significance of this research was to identify effective nursing interventions for patients who were experiencing anxiety whilst in hospital.
\end{abstract}

\section{Key words}

Mental health, Nursing intervention, Therapeutic relationship, Patient experiencing anxiety, Private hospital setting, Nursing skills

\section{I ntroduction}

There are many aspects of everyday life that provoke anxiety including being in hospitals ${ }^{[1]}$. Anxiety exists on a continuum from normal, which alerts us to those things we need to pay attention to in our environment. Anxiety is a subjective experience that signals a threat of some type and stimulates a stress response. Anxiety disorders are debilitating conditions known to cause considerable emotional and physical suffering and which has social as well as economic consequences ${ }^{[1]}$. Anxiety influences people's mood, expectations and motivation, and are the most prevalent mental disorders ${ }^{[2]}$. Anxiety may occur in the context of other mental health disorders. For instance, anxiety and depression 
commonly occur together ${ }^{[2,3]}$. However, mental health nurses possess a wide variety of holistic skills and there is evidence of nursing interventions that are proving to be valuable in treating anxiety in the community population ${ }^{[3]}$. Therefore, it is proposed that the nurse patient relationship is important and is a critical element within nursing's paradigm of patient care ${ }^{[4]}$. Regardless of where patients fall on the anxiety-continuum, nursing interventions can be therapeutically ${ }^{[2]}$ effective in this situation.

As nurses comprise the largest group of health care providers ${ }^{[5]}$ and are responsible for the quality patient care they provide to patients ${ }^{[6]}$, their perspectives on the effectiveness of their care is important. Many studies have discussed the impact of nursing on health care outcomes ${ }^{[7,8]}$ and these suggest that positive patient outcomes depend more on the skills of nurses than on the available technology ${ }^{[9]}$. Many investigators, managers and researchers have attempted, therefore, to define nursing's impact on and contribution to care ${ }^{[10]}$. Therefore, this study aims to explore nursing skills and models that nurses employ to ameliorate patients' anxiety. There is a need to define the nursing skills/or model of care used in the management of patient anxiety.

\subsection{Aims of the Study}

The aims of the study were to:

1) Explore nurses’ perceptions of their practices and skills in caring for patients experiencing anxiety;

2) Examine whether nurses practised a consistent approach to the management of patients experiencing anxiety in the two inpatient mental health facilities.

\subsection{Background of the Study}

In most countries, treatment of anxiety disorders are available through guidelines for mental health care ${ }^{[11]}$ such as, in general practice and in the area of psychology ${ }^{[12,13]}$, but research evaluating the effectiveness of nursing's therapies for patients experiencing anxiety are lacking ${ }^{[14]}$. However, for nursing staff, hospital policies and guidelines vary across each health setting and treatment/practice care may not always be in line with the standards provided under such guidelines ${ }^{[15]}$.

The Cochrane Database of Systemic Reviews ${ }^{[16]}$ on professional management of anxiety clearly identifies that the treatment of anxiety is traditionally delivered by mental health professionals, including psychologists, social workers, nurses and medical officers. However, there are no available set guidelines for specific nursing interventions, and there are a number of approaches followed by different professionals; one being the quality of the relationship with the patient and skills delivery ${ }^{[17]}$. Furthermore, nursing interventions have not always received adequate recognition by other health professionals ${ }^{[18]}$.

To claim that mental health nurses receive more skills training in building a therapeutic alliance is not the sole basis of the relationship between nurses and patients in dealing with challenging behaviour ${ }^{[19]}$. The nurse's relationship with patients is grounded in day-to-day therapeutic experiences rather than in any established theory or empirical research ${ }^{[19]}$. One of the significant factors in mental health nursing documented in the research studies of Dearing ${ }^{[20]}$ identified the importance of the nurse/patient relationship and considered this as a central concept for mental health nursing. However, research studies, which have focused on nursing interventions for patients experiencing anxiety, have been limited and nurses' involvement is unclear. Patton ${ }^{[21]}$ recommended that the impact of anxiety on an individual and nursing interventions need to be explored further.

In this context, it is important to explore what nurses do for patients in mental health care experiencing anxiety ${ }^{[17]}$. The Tidal Model ${ }^{[18]}$ has highlighted the centrality of interpersonal relationships within nursing practice. The principle of the model is to integrate into nursing processes, re-empowering individuals (the person) who experiences the feelings of helplessness (disempowered) through anxiety and distress. By employing the Tidal model the nurse engages and guides 
the person in the early stages of distress and begins the process of learning about what the person can do to manage their anxiety.

The quality of the nurse-patient relationship is considered important in nursing situations ${ }^{[22]}$ and in mental health nursing interpersonal interaction is the core of practice ${ }^{[23]}$, making the therapeutic relationship the essence of mental health care ${ }^{[24]}$. Moreover, the success of many interventions is reliant on the foundation of some form of therapeutic relationship ${ }^{[25]}$. For example, the development of a quality therapeutic relationship has been associated with the facilitation of solutions to various problems being experienced by patients ${ }^{[26]}$, improved medication compliance ${ }^{[27]}$ increased quality of life, and the achievement of better patient outcomes ${ }^{[28-29]}$.

Therefore findings around evidence-based nursing interventions from this study are desirable on both efficacy and efficiency grounds. The nurse's role needs clarification in a health care context where technical skills seem to be more eagerly sought than caring skills ${ }^{[30]}$. Nursing needs to ensure a distinction between what our colleagues offer and what nurses offer patients and the effectiveness of nursing interventions need to be identified.

\subsection{I mplications for practice}

1) Positive aspects of nursing strategies included assisting the patient to develop coping techniques and relapse prevention strategies, and that patients can ask for help.

2) The results demonstrated that it is important to improve patients' awareness of anxiety and how to access nurse's help at its onset.

3) The need for nurses to work closely with patients to develop de-stress strategies.

4) Recruitment of experienced staff is critical to improve patient outcomes.

\section{Methods}

The qualitative descriptive approach ${ }^{[31]}$ utilises in-depth interviews which allow nurses to share their perceptions about how they approach a clinical problem or situation in their clinical setting.

In the present study, in-depth face-to-face interviews were held with 30 nursing staff of both genders aged between 26-52 years of age who had consented to participate. There were 3 males and 27 females, and work experience ranged between 125 years. The mean age was 36 years. Interviews were tape recorded, unstructured but focused on individual nurses' perceptions of, reflections on, and experiences with patients experiencing anxiety.

\section{Data analysis}

The content of the interviews were recorded and transcribed verbatim and data were analyzed using content analysis to extract significant themes and sub-themes that captured the interventions utilised by nurses to manage patient's anxiety. The principle researcher carried out the initial coding and results were compared across theme members' coding data. Codes were allocated to categories and the overall themes were then formulated.

\section{Results}

Table 1 identifies the categories and concepts. The categories that emerged from the open-ended questions were Assessment skills, Communication skills, Being there for the patients which encompass the core concept of 'Therapeutic relationship'. The categories were identified as influencing factors that are most needed and vital for nursing including: 'Clarifying; Having a conversation; Showing empathy; Exploring alternatives; Grounding; Listening; Empowering the patient and Developing rapport. 
Table 1. Theme and categories

\begin{tabular}{ll}
\hline \multicolumn{2}{l}{ Therapeutic relationship with the patient } \\
\hline Categories & Influencing factors \\
\hline Assessment skills & Clarifying \\
& Developing rapport \\
Communication skills & Having a conversation \\
& Grounding \\
Being there for the patient & Listening \\
& Showing empathy \\
\hline
\end{tabular}

The process of developing an understanding of what was best for the patient included acknowledging patients as competent persons, a milieu-therapy culture based on objective information and reflective practice. Other categories linked to and embraced within this core category include Providing counselling and Holistic care and Promoting healing through the process of self-care.

Senior nurses in the study who stated that they preferred to work with and counsel their patients, avoid giving medication unless it was necessary.

\subsection{Themes}

\subsubsection{Assessment skills}

A fundamental aspect of the nurse's caring role is decision making which arises from assessment and monitoring of patients in order to carry out effective treatment plans and co-ordinate the involvement and contributions of other disciplines. It is therefore essential that the nurse has well-developed assessment skills. Experienced nurses who work with patients suffering from mental health problems often share a common characteristic with other experienced practitioners: the ability to 'sense' when something is not as it appears to be ${ }^{[30]}$.

As cited by two nurses: 'we know when something are not right,...gut feeling...,Establishing a relation with trust and understanding of the patient's problems... Supporting the patient to set goals....Making explicit expectations' ..... Finding the right mode of procedure ... ‘

Experienced nurses often recall and draw on experiences in the present situation. However, the inexperienced nurse will often be unsure about how to intervene during an acute stage of anxiety and will ask more experienced nurses for help.

\subsubsection{Communication skills}

Forchuk \& Reynolds ${ }^{[32]}$ asserts that the ability to listen well is the most helpful quality found in the person you go to see to talk about a personal or emotional problem. If mental health nurses are able to develop a therapeutic relationship with their patients by exercising 'good' interpersonal skills then they have successfully negotiated the first move in forming a therapeutic alliance. The ability to use active listening skills is the first step ${ }^{[33]}$. The process of demonstrating active listening through reflection of content and feeling, demonstrates a high level of empathy ${ }^{[34]}$. This is fundamental to the building and maintaining of therapeutic relationships. As one nurse stated 'Using varied ways of communication... conversation as a therapeutic tool... Using the body as a tool...'

\subsubsection{Being there for the patients}

The ability of the nurse to be flexible was an important feature of nurses' practice. According to another nurse 'staying with patients during their distress should help them to learn to gain control over their anxiety situations'. She emphasised the importance of the patients' being self- experts and their ability to 'share' their knowledge and experiences with others: 
'Maybe I am the person who has supported them in this process - but it is absolutely not me who is the expert anymore.' .... Balancing time to meet patient's need'....

The nurses expressed how they tried to create 'patient participation' in the management of their experience of anxiety. Nurses tried to foster a sense of control and this seemed to facilitate patients' beliefs in their own abilities. One nurse commented: 'We are working towards a way for patients to gain increased control over their symptoms....' The strategy used was made explicit to her (patient)' ....

\subsubsection{Therapeutic relationship with clients}

Given the current pressures on health care, where resources are often inadequate and time limited, nurses view their ability to provide care as hurried and superficial ${ }^{[29]}$. Less experienced nurses found it difficult to engage patients with acute anxiety. They felt overwhelmed and preferred to get support from more experienced nurses to deal with the patients. Mental health nurses believed that treating patients with dignity and respect provides the foundation for a quality therapeutic relationship. Nurses in the present study indicated they were "always being polite," "accepting patients for who they are and not as you would wish them to be", and "treating patients with dignity and respect". These findings support Rogers' ${ }^{[35]}$ concept of unconditional regard which is vital to relationship development and involves the therapist being non-judgmental and respecting, and accepting of the patients in a non-conditional manner regardless of the clients' behaviour.

Several nursing attributes were ranked as important with this group of mental health nurses when interacting with patients. For example, "giving patients options”, “remembering patients’ names”, "giving proper attention”, "introducing yourself to the patient" and "providing consistency in their contacts".

A number of statements implied that self-understanding was ranked as being relatively less important by mental health nurses in the study settings and included: "being aware of how you treat the patient”, "recognizing your own vulnerability" and "examining your motivations, values, beliefs and experiences". This finding was somewhat surprising, especially as some authors, e.g. Ecroth-Bucher ${ }^{[36]}$ have argued that knowing oneself is a fundamental principle of psychiatric nursing practice. A possible interpretation is that participants felt that other attributes were more important. Berg and Hallberg ${ }^{[37]}$ found that mental health nurses explained their practice in terms of doing rather than being. Another interpretation therefore is that nurses in the present study considered self-understanding as not important as other factors, and may represent the "doing" of mental health nursing. Another interpretation is that self-understanding is not something that nurses are consciously aware of and therefore not easily articulated. Scanlon ${ }^{[38]}$ stated nurses "sometimes act on instinct as opposed to any learned model of practice”.

By understanding the theory of human relatedness as a framework for nurse-patient relationships, nurses can better understand practice experiences and develop these therapeutic relationships with patients from a different perspective. The most effective intervention to improve quality of care as expressed by experienced nurses represents the belief that reflective practitioners will always treat patients with dignity. Participants believed self-understanding was important to relationship development and a quality therapeutic relationship included "being supportive" and "understanding the uniqueness of each patient's situation”. For example, factors that were ranked as less important included "acknowledging it is not possible to know how another person feels", "putting mechanisms in place to avoid detrimental responses" and "observing how others engage with the patients". It is possible, due to the immediacy of workplace demands and/or the "unconscious" practicing of self-awareness that these nurses were in fact self-aware but failed to identify that they were.

Whereas one nursing intervention may be beneficial for one client, it may not be beneficial or may even be harmful to another. Specific nursing interventions must be selected and tailored (individualized) to patients.

Table 2 provides an overview of strategies that nurses reflected on in their practice with patients who were experiencing anxiety. 
Table 2. Nursing interventions for the management of anxiety

1) Explore the patient's perceptions of symptoms

2) Correct any misconceptions about anxiety

3) Assist the patient to identify past successful coping mechanisms

4) Help the patient to identify and make use of available support systems

5) Encourage the patient to share his or her thoughts, feelings, beliefs, and concerns with someone who is supportive and making one-self available to the patient

6) Listen attentively

7) Convey empathy

8) Teach the patient to recognize the symptoms of anxiety

9) Teach the patient more therapeutic interpersonal skills; encourage patients to ask for help when needed and avoid false reassurance

10) Teach interventions to the patient that may be useful in decreasing anxiety (e.g. positive self talk, deep breathing, progressive muscle relaxation, and massage)

11) Educate the patient about anxiolytics and other prescribed medications

12) Provide a quiet and calm environment during periods of increased anxiety

13) Being with the patient during periods of increased anxiety

14) Refer the patient to therapy support groups

Nursing becomes necessary when the person becomes unable to maintain self-care that sustains life and health, in recovering from disease or injury or in coping with the effects of anxiety.

Results from research studies indicate that there was a very broad range of nursing practices employed by mental health nurses to develop a therapeutic relationship and implement effective interventions for patients experiencing anxiety. In the present study, members' opinion was that health service benefits from having a mix of nurses from different levels of experience, age groups and from both genders to be effective in working with patients experiencing acute anxiety. However, it was highlighted that nurses might experience difficulties with younger patients who may be sensitive to power and privacy issues. Adolescent patients, it was felt, might respond better to younger nurses.

\section{I mplications for nursing practice}

The present study has confirmed that the essence of mental health nursing lies in the therapeutic relationship. Positive regard allows nurses to view all people we work with as both unique and worthy of our effort.

These research findings are in line with other studies. Up-skilling of mental health nurses is crucial to strengthen professional skills and lead to more effective patient outcomes. Improving collaboration between mental health professionals may resolve inter-professional problems, and problems for practice related to institutional policies and procedures.

\section{Conclusion}

The results indicate that nurses perception of their nursing interventions in relieving anxiety in the study setting had confirmed the importance of counselling skills based within the context of the 'therapeutic relationship'. The study indicates that mental health nursing practice is a combination of knowledge and learned experiences through the 
acquisition of interpersonal skills. Working with a person who is experiencing anxiety requires in-depth theoretical and personal knowledge that is acquired only by experience.

\section{Recommendation}

Future research is required to confirm the study findings in similar inpatient settings. Research should focus on the impact of context and the long-term benefits of encouraging organizations to employ more experienced nurses that best match the needs of patients. In return, beliefs congruent with practice may have an impact upon the work satisfaction and retention of nurses.

\section{Acknowledgement}

We would like to acknowledge St John of God Health Care for the funding of this study and to all the nursing staff who participated.

\section{References}

[1] Andrews, G., Henderson, S. Unmet need in psychiatry. Problems, resources, responses. Cambridge: Cambridge University Press. 2000. http://dx.doi.org/10.1017/CBO9780511543562

[2] Elder, R., Evans, K., Nizette, D. Psychiatric and mental health nursing. 2nd ed. Sydney: Elsevier. 2009.

[3] Cooper, L. A., Brown, C., Vu, H. T., Palenchar, D. R., Gonzales, J. J., Ford, D. E., et al. Primary care patients' opinions regarding the importance of various aspects of care for depression. General Hospital Psychiatry. 2000; 22: 163-173. http://dx.doi.org/10.1016/S0163-8343(00)00073-6

[4] Fawcett, J. Analysis and evaluation of conceptual models of nursing (3rd ed.). Philadelphia: Davis. 1995.

[5] Brooten, D. Youngblut, JoAnne M. Nurse Dose as a Concept. Journal of Nursing Scholarship. 2006; 38: 1: 94-99. PMid:16579330 http://dx.doi.org/10.1111/j.1547-5069.2006.00083.x

[6] England, M. Review of Psychotherapy for the advanced practice psychiatric nurse. Perspectives in Psychiatric Care. 2008; 44(3): 219-220. http://dx.doi.org/10.1111/j.1744-6163.2008.00179.x

[7] Lankshear, A, Sheldon, T, Maynard, A. Nurse Staffing and Healthcare Outcomes: A Systematic Review of the International Research Evidence. Advances in Nursing Science. 2005; 28 (2): 163-174. PMid:15920362

[8] Bolton, L.B., Aydin, C.E., Donaldson, N., Brown, D.S., Nelson, M.S. and Harms, D. "Nurse staffing and patient perceptions of nursing care”, Journal of Nursing Administration (JONA). 2003; 33 (11): 607-14. http://dx.doi.org/10.1097/00005110-200311000-00011

[9] Navuluri, R.B. Integrated quality improvement program in patient care. Nursing and Health Sciences. 1999; 1(4): $249-54$. http://dx.doi.org/10.1046/j.1442-2018.1999.00028.x

[10] Chang, B.L., Lee, J.L., Pearson, M.L., Kahn, K.L., Elliott, M.N. and Rubenstein, L.L. Evaluating quality of nursing care: the gap between theory and practice. Journal of Nursing Administration (JONA). 2002; 32 (7/8): 405-18.

http://dx.doi.org/10.1097/00005110-200207000-00009

[11] Ballenger JC, Davidson JR, Lecrubier Y, et al. Consensus statement on generalized anxiety disorder from the International Consensus Group on Depression and Anxiety. J Clin Psychiatry. 2001; 62(Suppl 11): 53-58.

[12] Andrews G, Davis M, Titov N. Effectiveness randomized controlled trial of face to face versus Internet cognitive behaviour therapy for social phobia. Australian and New Zealand Journal of Psychiatry. 2011; 45(4): 337-340. PMid:21323490 http://dx.doi.org/10.3109/00048674.2010.538840

[13] Bushnell J, Gellatly R, Oakley-Browne M, et al. Guidelines for assessing and treating anxiety disorders. Wellington: National Health Committee. 1998.

[14] Bebbington P, Brewin CR, Marsden L, Lesage A. Measuring the need for psychiatric treatment in the general population: the community version of the MRC Needs for Care Assessment. Psychol Med. 1996; 26(2): 229-236. http://dx.doi.org/10.1017/S0033291700034620

[15] Heideman, J., van Rijswijk, E., van Lin, N. et al. Interventions to improve management of anxiety disorders in general practice: a systematic review. Br J Gen Pract. 2005; 155(520): 867-873.

[16] Hunot V, Churchill R, Teixeira V, Silva de Lima M. Psychological therapies for generalised anxiety disorder. Cochrane Database of Systematic. Reviews. 2007; 3.

Published by Sciedu Press 
[17] Jones A. The value of Peplau's theory for mental health nursing. Br J Nurs. 1996; 5(14): 877-81. PMid:8718356

[18] Barker, P. The Tidal Model: developing an empowering, person-centred approach to recovery within psychiatric and mental health nursing. Journal of Psychiatric \& Mental Health Nursing. 2001; 8(3):233-240. PMid:11882132 http://dx.doi.org/10.1046/j.1365-2850.2001.00391.x

[19] Shanley, E; Jubb-Shanley, M. The recovery alliance theory of mental health nursing. Journal of Psychiatric and Mental Health Nursing 2007; 14(8): 734-743. PMid:18039296 http://dx.doi.org/10.1111/j.1365-2850.2007.01179.x

[20] Dearing, M. Getting it, together: how the nurse patient relationship influences treatment compliance for patients with schizophrenia. Arch Psychiatr Nurs. 2004; 18(5): 155-63. PMid:15529280 http://dx.doi.org/10.1016/j.apnu.2004.07.002

[21] Patton D. Reality orientation: its use and effectiveness within older person mental health care. J Clin Nurs. 2006; 15(11):1440-9. PMid:17038105 http://dx.doi.org/10.1111/j.1365-2702.2005.01450.x

[22] Forchuk, C., \& Reynolds, W. Clients’ reflections on relationships with nurses: Comparison from Canadian and Scotland. Journal of Psychiatric and Mental Health Nursing. 2001; 18: 4551.

[23] Cleary, M., Edwards, C., Meehan, T. Factors influencing nurse patient interaction in the acute psychiatric setting: An exploratory investigation. Australian and New Zealand Journal of Mental Health Nursing. 1999; 8:109-116. PMid:10661080 http://dx.doi.org/10.1046/j.1440-0979.1999.00141.x

[24] Priebe, S., Gruythers, T. The role of the helping alliance in psychiatric community care: A prospective study. Journal of Nervous and Mental Disease. 1993; 181: 552-557. PMid:8245923 http://dx.doi.org/10.1097/00005053-199309000-00004

[25] Pedersen, G. Karterud, S. Associations between patient characteristics and rating of treatment milieu. Nordic Journal of Psychiatry. 2007; 4: 271-278. PMid:17763120 http://dx.doi.org/10.1080/08039480701414999

[26] Kai, J., Crosland, A. People with enduring mental health problems describe the importance of communication, continuity of care, and stigma. Evidence Based Mental Health. 2001; 5(2): 62-63.

[27] Pinikahana, J., Happell, B., Taylor, M., Keks, N. A. Exploring the complexity of compliance in schizophrenia. Issues in Mental Health Nursing. 2002; 23: 513-528. PMid:12079602 http://dx.doi.org/10.1080/01612840290052677

[28] Hagerty, B. M., Patusky, K. L. Reconceptualizing the nurse patient relationship. Journal of Nursing Scholarship. 2003; 35(2): 145-150. PMid:12854295 http://dx.doi.org/10.1111/j.1547-5069.2003.00145.x

[29] Dziopa, F. Ahern, K. Three Different Ways Mental Health Nurses Develop Quality Therapeutic Relationships. Issues in Mental Health Nursing. 2009; 30:14-22. PMid:19148817 http://dx.doi.org/10.1080/01612840802500691

[30] Shattell, M. Nurse-patient interaction: a review of the literature. Journal of Clinical Nursing. 2004; 13: 714-722. PMid:15317511 http://dx.doi.org/10.1111/j.1365-2702.2004.00965.x

[31] Polit, D. Beck, C. Essentials of Nursing Care: Methods, Appraisal and Utilization. 6th edn. Lippincott Williams and Wilkins, Philadelphia. 2006.

[32] Forchuk, C., Reynolds, W. Clients’ reflections on relationships with nurses: Comparison from Canadian and Scotland. Journal of Psychiatric and Mental Health Nursing. 2001; 8: 45-51. PMid:11879493 http://dx.doi.org/10.1046/j.1365-2850.2001.00344.x

[33] Welch, M. Pivotal moments in the therapeutic relationship. International Journal of Mental Health Nursing. 2005 ; $14:$ 161-165. PMid:16181152 http://dx.doi.org/10.1111/j.1440-0979.2005.00376.x

[34] Lloyd, M. Empowerment in the interpersonal field: Discourses of acute mental health nurses. Journal of Psychiatric and Mental Health Nursing. 2007; 14(5): 485-494. PMid:17635257 http://dx.doi.org/10.1111/j.1365-2850.2007.01116.x

[35] Rogers, C. The interpersonal relationship: The core of guidance. In C.Rogers \& B. Stevens (Eds.). A new trend in psychology. New York: Pocket Books. 1971; 85-101.

[36] Ecroth-Bucher, M. Philosophical basis and practice of self awareness in psychiatric nursing. Journal of Psychosocial Nursing and Mental Health Services. 2001; 39(2): 32-39.

[37] Berg, A., Hallberg, I. R. Psychiatric nurses’ lived experiences of working with inpatient care on a general team psychiatric ward. Journal of Psychiatric and Mental Health Nursing. 2000; 7: 323-333. PMid:11933404 http://dx.doi.org/10.1046/j.1365-2850.2000.00307.x

[38] Scanlon, A. Psychiatric nurses perceptions of the constituents of the therapeutic relationship: A grounded theory study. Journal of Psychiatric and Mental Health Nursing. 2006; 13: 319-329. PMid:16737499 http://dx.doi.org/10.1111/j.1365-2850.2006.00958.x 